\title{
PUSTAKAWAN, TUNJUKKAN GREGETMU!
}

\section{Oleh: Euis Rosinar}

\begin{abstract}
Abstrak
Era lama Pustakawan akan segera berakhir. Pustakawan berparadigma baru sudah saatnya menghidup-cerahkan Undang-undang Republik Indonesia Nomor 43 Tahun 2007 tentang Perpustakaan. Selama tiga puluh tahun profesi Pustakawan berkiprah, citra melekat yang kurang pas harus bergeser ke arah yang sebenarnya, yaitu pencerahan citra di satu sisi dan pengakuan masyarakat luas di sisi lainnya. Di Negara-negara maju, perpustakaan menjadi satu-satunya cerminan "kelas" sebuah lembaga pendidikan. Di Indonesia, jargon "jantungnya pendidikan" menjadi populer secara terabaikan: jantung yang sakit dan dibiarkan tetap berdenyut seadanya. Era tahun 1980-1990 menandai suramnya Pustakawan dengan citranya yang terpinggirkan. Citra yang berbanding terbalik dengan keadaan dimana Pustakawan adalah bagian elit politik dan berkedudukan sangat strategis sebagai sosok kepercayaan para penguasa pemerintahan. Profesi yang dilabelkan sebagai A Feminine Profession di sebuah Negara adidaya karena 83\% Pustakawannya adalah wanita, perlu memanfaatkan peluang untuk justru menampilkan sisi cerdas seorang berprofesi Pustakawan tanpa harus mengusung citra wanita secara universal. Momen penting ini akan berupa semakin banyaknya jumlah Pustakawan di Indonesia karena mulai tahun 2013 seluruh sekolah dari tingkat SD sampai SMA/K harus memiliki perpustakaan yang dikelola dan ditangani Pustakawan murni - seseorang berpendidikan ilmu perpustakaan dan tuntasfokus didalam pekerjaan profesinya. Seperti Dokter, Guru, dan Dosen, para Pustakawan ini akan bersertifikasi untuk apa yang sepatutnya dilabelkan yaitu berkiprah secara kompeten dan professional seutuhnya. Saatnya sudah tiba untuk para professional yang pernah terpinggirkan ini untuk menunjukkan gregetnya atau "taringnya". Perlu ditunjukkan bahwa Bunny Watson - Bunny Watson baru akan bermunculan dan mencerahkan.
\end{abstract}

Kata Kunci: Pustakawan

\section{A. Pendahuluan}

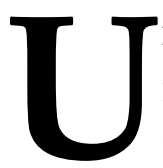

Undang merupakan produk hukum tertinggi dan dipergunakan sebagai dasar berpijak dan mengambil keputusan untuk hal yang berkaitan dengan UU tersebut. Perihal kepustakawan di Indonesia yang selama bertahun tahun menunggu acuan berpijak untuk mengatur segala urusan perpustakaan akhirnya mendapatkan pencerahan. UndangUndang Perpustakaan No. 43 yang disyahkan pada tanggal 1 November 2007 disambut dengan baik oleh kalangan Pustakawan dan pengelola perpustakaan. Kepastian tentang status pustakawan kini 
telah dijamin penuh oleh UU tersebut.

Dalam UU Perpustakaan, diberi kepastian hukum bahwa Pustakawan berhak memimpin perpustakaan seperti yang tertuang didalam pasal 30 yang mengamanatkan

"Perpustakaan bahwa Perpustakaan Umum Pemerintah, Perpustakaan Umum Provinsi, Perpustakaan Umum Kabupaten/Kota, dan Perpustakaan Perguruan Tinggi dipimpin oleh Pustakawan atau tenaga ahli dalam bidang perpustakaan". Pustakawan tidak saja diberi hak untuk memimpin perpustakaan tetapi juga berhak mendapat promosi sesuai yang termaktub didalam pasal 31 huruf $b$ : "Pembinaan karir sesuai dengan tuntutan pengembangan kualitas". Amanat UU tersebut dengan jelas telah tertuang. Tetapi nampaknya perintah UU tersebut belum dapat diterima. Apa yang sebenarnya sedang terjadi?

Teknologi informasi berkembang begitu pesat tetapi mengapa Pustakawan nampaknya masih menjadi sosok yang terpinggirkan. Peran dan sumbangsih yang diberikan Pustakawan begitu besar dalam pencapaian misi perpustakaan maupun institusi induk dimana perpustakaan itu bernaung. Produk-produk yang dihasilkan oleh perpustakaan seperti repository mampu mendongkrak citra institusi induk ke posisi yang lebih baik melalui penilaian peringkat Webometric yang menempatkan posisi lembaga secara keseluruhan. Kerja keras Pustakawan untuk meningkatkan citra institusi induk tidak dibarengi dengan pemberian penghargaan atau perhatian penuh dari pemegang tampuk pimpinan tertinggi atau paling tidak pengakuan akan eksistensi dan kontribusi Pustakawan. Tidak cukupkah sumbangsih Pustakawan?

Peran Pustakawan yang begitu besar masih belum mendapat pengakuan sampai hari ini. Masih banyak Pustakawan yang belum mendapatkan posisi strategis. Standar kualifikasi untuk Pustakawan telah ditetapkan. Ketentuan mengenai tugas dan tanggung jawab telah jelas dipaparkan. Organisai profesi Pustakawan telah lebih dari 30 tahun berkiprah. Pustakawan bergelut dengan perangkat komputer setiap hari, mengurus basis data, mengurus masalah administratif perpustakaan dan selalu memastikan bahwa semua sistem yang ada berfungsi dan berjalan sebagaimana mestinya. Tetapi mengapa orang masih mempunyai persepsi abad pertengahan tentang keberadaan dan sosok Pustakawan? Mengapa 
pengakuan terhadap Pustakawan belum juga didapatkan? Tidak layakkah Pustakawan mendapat mandat? Ada apa dengan Pustakawan?

\section{B. Pustakawan, Siapa Mereka?}

"We are librarians, and therefore the elect of God.

To read is human, to catalogue divine" -Charity Blackstock, Dewey Death (1956-)

Sosok Pustakawan telah tampil di banyak film layar lebar dan televisi. Hollywood telah banyak menghasilkan karya sinematografi dengan menampilkan sosok Pustakawan sebagai tokoh utama. Sejak tahun 50an telah puluhan film tentang Pustakawan diproduksi. Bintang-bintang besar dari era tahun 50 sampai tahun 2000, dari si cantik Katharine Hepburn sampai Rachel Weisz, memerankan tokoh seorang Pustakawan. Karakter Pustakawan digambarkan beragam, mulai dari karakter yang konservatif sampai karakter cerdas. Di layar televisi sosok Pustakawan diwakili oleh Rupert Giles yang bekerja di Sunnydale High school dalam film Buffy the Vampire Slayer.

Tokoh-tokoh besar dunia yang peduli pada pendidikan dengan mencurahkan segenap tenaganya memajukan pendidikan lewat perpustakaan dan sekaligus menjadi Pustakawan pada masanya telah dicatat dan menjadi bagian dalam sejarah dunia. Benjamin Franklin, the Founding Father Amerika Serikat yang menandatangani lima dokumen penting kemerdekaan: the Declaration of Independence, the Treaty of Amity and Commerce with France, the Treaty of Alliance with France, the Treaty of Peace with Great Britain, dan the Constitution of the United States of America. Laura W. Bush mantan Ibu Negara Negara adidaya Amerika, Pope Pius XI sang pemimpin tertinggi kaum Katholik di dunia, Golda Meir mantan Perdana Menteri wanita Israel, Mao Tse-Tung seorang pemimpin besar partai komunis Cina, dan Casanova seorang pecinta ulung adalah sebagian kecil dari sejumlah tokoh dunia yang dikenal publik karena kiprah yang mereka lakukan kemudian. Jauh sebelum perpustakaan berkembang seperti sekarang, pada tahun 1731, Benjamin Franklin adalah pendiri perpustakaan pertama di Amerika yang memberikan pelayanan peminjaman kepada umum dan sekaligus bertindak sebagai Pustawakan. Laura W. Bush adalah seorang Pustakawan di Austin's Dawson Elementary School. Pope Pius XI adalah chief librarian di sekolah seminari di Milan, Golda 
Meir adalah Pustakawan di Milwaukee dan Chicago, Mao TseTung pada tahun 1918 menduduki posisi sebagai chief librarian di Universitas Peking dan Casanova sebelum dikenal sebagai penakluk wanita, selama 13 tahun bekerja sebagai Pustakawan untuk Count von Waldstein di the Chateau of Dux di Bohemia.

Pustakawan bukan seseorang yang hanya duduk di kursi kerja masing-masing sambil menunggu Pemustaka yang datang untuk meminjam ataupun mengembalikan buku. Pustakawan bukan penjaga buku, pustakawan adalah sebenarbenarnya frontier di perpustakaan, The Librarians are the guardians of powerful and magical relics, and have been for centuries, and often undertake global-spanning adventures to recover items and store them in the Library (http://en.wikipedia.org/wiki/The_L ibrarian_\%28franchise\%29).

Menurut the American Library Association, www.ala.org 'librarians decide what items to discard or purchase, help individuals with research questions and homework, offer training and programs, build websites, help people use the Internet, and more. Librarians who specialize may work with non-English speaking populations and seniors, run computer systems, specialize in certain subject area, or maintain the online catalog records.'

$$
\text { Mereka yang tidak }
$$
mempunyai gelar dr (dokter medis) dan bekerja di kantor seorang dokter tidak pernah dan tidak berhak dipanggil dokter; karyawan sebuah sekolah yang tidak mempunyai latar belakang dan ijasah dalam bidang pendidikan dianggap tidak berkualifikasi untuk menjadi seorang guru dan tidak berhak disebut guru, begitu juga dengan sebutan Pustakawan. Lebih dari seseorang yang berdiri di garis depan dan sebagai mediator antara koleksi dengan Pemustaka, seorang Pustakawan adalah seorang profesional. Latar belakang pendidikan seorang Pustakawan harus ditempuh melalui jalur pendidikan formal ilmu perpustakaan dan informasi. 'A librarian is an information professional trained in library and information science, which is the organization and management of information services or materials for those with information needs.' http://www.pemustaka.com/pustak awan.

Sekolah-sekolah bidang perpustakaan dan informasi, pascasarjana khususnya, telah memberi keleluasaan kepada para Mahasiswa untuk memilih bidang keahlian masing-masing. Di McGill University (universitas terbaik di Kanada, Top Twenty di Amerika 
Utara) misalnya, kepada Mahasiswa diberi tiga pilihan bidang keahlian yang digelutinya yaitu archives, knowledge management, dan librarianship. Apakah lulusan sekolah ilmu perpustakaan akan menjadi Arsiparis, ahli knowledge management, ataupun menjadi Pustakawan, tetap saja mereka adalah bagian dari perpustakaan.

Pustakawan bekerja secara profesional dengan memfokuskan diri pada satu dari tiga aspek bagian pekerjaan yang ada di perpustakaan sesuai dengan kompetensinya yaitu 1) aspek pelayanan pemustaka, 2) aspek pelayanan teknis, dan 3) aspek pelayanan administratif. Pustakawan di bidang pelayanan Pemustaka membantu Pemustaka mendapatkan informasi yang diperlukan. Pustakawan di bidang pelayanan teknis melakukan kegiatan pengadaan koleksi, pengolahan koleksi, dan menyiapkan alat telusur seperti katalog untuk memudahkan Pemustaka mengakses berbagai sunmber informasi di perpustakaan sehingga kebutuhan informasi yang diinginkannya terpenuhi. Di bidang pelayanan administratif, Pustakawan memusatkan pekerjaan pada kegiatan manejerial dan perencanaan perpustakaan. Mereka melakukan negosiasi kontrak dengan pemasok koleksi dan peralatan, melakukan supervisi kepada staf perpustakaan, melakukan hubungan masyarakat, dan menyiapkan pendanaan untuk perpustakaan serta memastikan bahwa semua sistem yang ada di perpustakaan berjalan dengan semestinya.

Sebutan untuk para Pustakawan beraneka ragam tergantung pada tempat di perpustakaan dimana mereka bekerja. Pustakawan perguruan tinggi bekerja di perpustakaan perguruan tinggi, Pustakawan sekolah adalah sebutan untuk mereka yang bekerja di perpustakaan sekolah, Pustakawan anak-anak / children librarian dan pustakawan remaja / young adult librarian berkerja di bidang koleksi remaja di perpustakaan umum. Sebagian Pustakawan ada yang bekerja pada kelompok tertentu sehingga disebut sesuai dengan keahlian khusus yang digelutinya.

\section{Citra Melekat Pustakawan}

Although the power of the crone may indeed be something librarians can hold onto, most women do not want to be associated with an image of a woman who is unattractive. Nor do male librarians like their own stereotypes (Morrisey and Case, 1988;

Carmichael, 1992) 
Image / citra merupakan bagian penting yang tidak bisa dilepaskan dari diri seseorang ataupun sekelompok orang. Webster menjabarkan image sebagai "a carved, painted or drawn effigy of a person or thing". Merriam-Webster menyebutkan image seagai "a mental picture or impression of something". Bertahun-tahun lamanya sosok pustakawan selalu dibicarakan dengan nada miring dan tidak penah berubah menjadi sosok yang "terpuji". Sudah ratusan artikel ditulis dan puluhan film diproduksi tetapi tetap saja hasil tulisan maupun film lebih banyak menampilkan sosok Pustakawan dari sisi yang kurang pas dibandingkan sisi positifnya. Pemberitaan di media, penayangan film layar lebar dan televisi bersumbangsih besar didalam mempengaruhi publik tentang pencitraan sosok Pustakawan. Hal ini sesuai dengan dekskripsi Matta dalam Membangun Citra Pustakawan bahwa citra adalah kesan imajinatif yang terbentuk dalam benak publik dalam rentang waktu tertentu dan terbentuk oleh keseluruhan informasi tentang diri kita yang sampai ke publik. Kesan imajinatif yang terbentuk telah memasung Pustakawan selama bertahun tahun.

Jasa pustakawan terabaikan begitu saja dan tidak diperhitungkan untuk masuk kedalam nominasi kriteria yang berimbas sebagai andil positif didalam pemberitaan. Pekerjaan Pustakawan didalam melayani kebutuhan informasi bagi Pemustaka selalu dianggap sebagai pekerjaan yang memang seharusnya dilakukan begitu saja. Pendapat dan perlakuan masyarakat membuat Pustakawan merasa tidak nyaman dan frustrasi teramat dalam. Penggambaran sosok Pustakawan tidak lebih dari seorang tua yang pekerjaannya menyusun buku dan membubuhkan setempel pada slip pengembalian buku apabila ada peminjam yang memerlukan koleksi untuk dibawa pulang. Sosok yang dilukiskan kurang terhormat, tidak menarik, dan tidak untuk dikagumi. Keadaan ini membelenggu sampai hari ini. Stereotype tersebut kian melekat pada diri Pustakawan karena tidak ada upaya diri melakukan pembelaan untuk memutus mata rantai pencitraan yang kurang pas. Keadaan diam Pustakawan menjadi 
alat jastifikasi dan membuat publik semakin diyakinkan bahwa sosok Pustakawan memang seperti yang digambarkan selama ini. Posisi bungkam dan terkesan tidak peduli menjadi semacam pembenaran terhadap semua tulisan dan tontonan yang beredar di masyarakat. Cram berpendapat dalam Librarians' Image And Identity: A Research Proposal about the Professional Community of Poletti Library "there is a sort of "vicious circle": we deplore our lack of visibility but we don't react, cherishing our negative image".

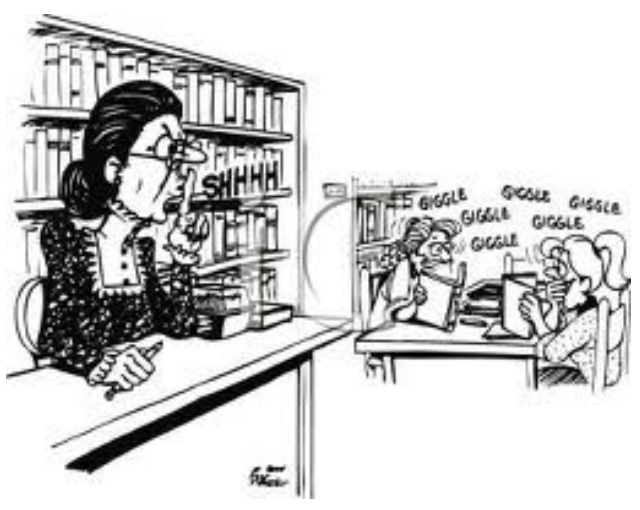

Pustakawan perempuan lebih menarik dijadikan obyek pembicaraan dan lebih banyak dikupas sepak terjangnya, mulai dari penampilan, make up, sampai perilaku keseharian. Status dan pergaulan sosial mereka dalam masyarakat tak luput dari perhatian publik. Memang tidak semua tontonan Hollywood menampilkan "sisi gelap" Pustakawan tetapi itu hanya satu atau dua film saja. Diantara produksi yang patut diacungi dua jempol adalah saat Hollywood memproduksi film berjudul Desk Set yang dibintangi aktris terkenal Katharine Hepburn. Film ini menggambarkan tentang sosok Pustakawan perempuan di bagian reference yang ideal dan hebat, Bunny Watson. Miss Watson tidak saja cantik tetapi juga cerdas, dapat mengingat hampir semua koleksi yang ada di perpustakaan dan mampu menjawab pertanyaan apa saja yang diajukan Pemustaka kepadanya. Kecerdasan dipadu dengan kecantikan membuat pria terutama kagum dan hormat kepadanya. Diantara banyak pria pengagumnya, ada dua pria yang selalu mengejar dan berusaha mendapatkan perhatian khusus dari dirinya. Dari kehidupan Miss Watson pada masa 50an, model Pustakawan wanita idaman lain yang hidup di akhir era 90an adalah Evie Carnahan dalam film the Mummy. Evie mampu membaca naskah dalam tulisan Mesir kuno. Selain cantik dan pintar, Evie 
dikenal sebagai sosok yang kuat dan pemberani.

Model wanita idaman yang digambarkan Hollywood tidak cukup mewakili pencitraan positif Pustakawan dan tidak merubah apapun tentang pandangan awam terhadap sosok Pustakawan perempuan. Stereotype, istilah yang selalu dipergunakan. Istilah itu melekat pada diri Pustakawan perempuan hingga sekarang. Gambaran umum selalu dilukiskan sebagai sosok tua berkacamata karena terlalu sering membaca sehingga penglihatannya terganggu, rambut dikonde, duduk di belakang meja sambil membaca, dan selalu meletakkan jari di mulut dengan mengeluarkan 'sssttt...' tatkala ada Pemustaka yang mengobrol dan ribut. 'The typical image is that of an asexual frumpy female wearing glasses and her hair up in a bun. She is often seen shushing patrons or otherwise acting grumpy'. (http://liswiki.org/wiki/Image_of_li brarians). Sosok ini diperburuk dengan tampilnya sosok Pustakawan bernama Marian dalam The Music Man. Marian adalah seorang Pustakawan yang bekerja di perpustakaan umum di River City, Iowa, Amerika Serikat. Sosok Marian digambarkan selanjutnya dengan "She is a young, attractive woman with glasses and her hair pulled back. She tends to look down on the members of the community, because they do not listen to her advice about which books are good. She does "shhh" patrons a few times during the course of the movie. She is fairly high strung, but does loosen up on a few occasions". (Librarians in the Movies, http://www.slais.ubc.ca/courses/libr 500/03-04-

wt1/assignments/www/K_Mulhern/ movies.htm).

Profesi pustakawan banyak dikuasai oleh perempuan, maka tidak mengherankan apabila profesi Pustakawan disebut sebagai A Feminine Profession. Dari data Pustakawan Amerika tahun 18802009, 83\% Pustakawan di Amerika adalah perempuan dan kenaikan jumlah Pustakawan laki-laki pada tahun 1930 hanya 8\%. Sementara hasil survey yang dilakukan oleh James V. Carmichael, Jr. didapatkan data bahwa over three quarters of the respondents $(77 \%)$ were aware of the numerical predominance of women in librarianship when they 
entered the profession. Walaupun Pustakawan laki-laki tidak banyak mempermasalahkan penggambaran sosok mereka, tetap saja sosok mereka di mata publik tak jauh berbeda dengan gambaran sosok Pustakawan perempuan. Tercuplik dari Wikipedia: "Stereotypes of librarians in popular culture are frequently negative: librarians are portrayed as ... or timid, unattractive, and effeminate if male". Dalam film Black Mask yang dibintangi Jet Li yang berperan sebgai Pustakawan bernama Tsui, digambarkan bahwa Tsui mempunyai karakter yang berbeda saat dia melaksanakan tugas keseharian sebagai Pustakawan, saat dia berkumpul dengan teman-temannya, dan saat dia berperan sebagai seorang jagoan. Saat berkumpul dengan teman-temannya, Tsui bisa dengan bebas bercanda dan tertawa. Tsui juga mampu bertarung melawan musuh-musuhnya tanpa terluka. Tetapi saat bekerja sebagai Pustakawan, Tsui adalah karakter yang berbeda. Dia menjadi seseorang yang pemalu dan tidak pernah bersosialisasi. Hal ini dikuatkan dengan hasil survey yang dilakukan oleh James V.
Carmichael, Jr.: the next most frequently chosen stereotypes, identified by over half of 352 respondents, related to lack of social skills and power (59\%) and lack of ambition (55\%). Typical of the descriptions of the powerless/socially inept types on which subjects elaborated were "nerd," "anal retentive, boorish, dull"; "humorless dweebs," and "wimp".

Acara "Family Freud" pernah melakukan survei tentang karakteristik Pustakawan terhadap 100 orang. Dari jawaban 100 orang yang disurvei, disimpulkan bahwa ada lima karakter utama Pustakawan yang paling banyak disebutkan yaitu: 1) diam, 2) tidak ramah, 3) lajang / tidak menikah, 4) stuffy, dan 5) berkacamata. (Kirkendall 1986 dalam Stephen Walker and V. Lonnie Lawson, The Librarian Stereotype And The Movies)

\section{Pustakawan Tidak Populer}

Librarians suffer from the Calimero Syndrome: as the black and unlucky chick, they adopt a plaintive and passive attitude of renunciation.

We cry because we don't have money, administrators don't appreciate our work, bureaucracy stops our ideas, users don't deserve our efforts. 
(Rasetti) terang terangan mengaku bahwa

Kedudukan Pustakawan masa kini jauh tertinggal dari profesi lainnya. Tak banyak orang di luar dunia perpustakaan mengenal Pustakawan. Tak ada anak yang mau menjawab ingin menjadi Pustakawan setiap kali ditanya tentang cita-cita mereka kelak. Bahkan, tidak ada Pustakawan yang dirinya Pustakawan dan bangga akan profesinya. Dibanding profesi lainnya, profesi Pustakawan menduduki 'strata' yang paling rendah secara finansial. Tabel dibawah ini menunjukkannya dengan jelas. Hal ini menjadi pemicu mengapa banyak lulusan program studi ilmu perpustakaan tidak mau menjadi Pustakawan.

\begin{tabular}{|c|l|c|c|}
\hline No. & Jenis jabatan & Jenjang jabatan & Tunjangan jabatan \\
\hline 1 & Peneliti & Utama & 1.230 .000 \\
\hline 2 & Perencana & Utama & 1.230 .000 \\
\hline 3 & Perekayasa & Utama & 1.230 .000 \\
\hline 4 & Pranata Komputer & Utama & 1.100 .000 \\
\hline 5 & Pustakawan & Utama & 700.000 \\
\hline
\end{tabular}

Sumber: Perundang-Undangan. http://www.presidenri.go.id/index.php/uu/peraturan-presiden/ (Akses 4 Januari 2012)

Kejayaan Pustakawan masa kini sangat bertolak belakang dibandingkan keadaan masa lampau. Sejarah mencatat bahwa pada jaman Mesir kuno, Pustakawan mempunyai nama harum dan mendapat kedudukan yang terhormat. Sejarah juga mencatat bahwa Pustakawan selalu menjadi bagian dari elit politik yang kedudukannya sejajar dengan para pemangku kepentingan. Rasanya tidak mengherankan apabila masa itu Pustakawan menjadi penasehat para penguasa. Dalam kehidupan spiritual, Pustakawan berada pada barisan yang sama dengan para ahli agama. 
Ikatan Pustakawan Indonesia (IPI) telah lama eksis. Pustakawan telah mencurahkan segenap jiwa raganya untuk perpustakaan dan memberikan segenap kemampuannya untuk selalu memberikan kemudahan kepada Pemustaka dalam memenuhi kebutuhan informasinya dengan memanfaatkan perkembangan teknologi informasi seperti yang ditegaskan oleh Cram dalam Librarians' Image and Identity: A Research Proposal about the professional community of Poletti Library: "we worry more about our libraries than we do about ourselves. We promote them, dead things as they are, while ignoring or at best only briefly unknowledging those who make libraries and their services live" Tetapi, mengapa Pustakawan tidak serta merta menjadi populer?

Di Indonesia, pada era 80 sampai 90an, perpustakaan menjadi tempat pembuangan bagi siapa saja yang tidak mampu melaksanakan fungsinya sampai karir kepegawaian mereka berakhir. Pustakawan sendiri memberikan andil besar terhadap pencitraan diri Pustakawan selama ini. Pustakawan yang menyelesaikan tingkat pendidikan yang tinggi meninggalkan perpustakaan dan lebih memilih profesi lain yang lebih menjanjikan dan prestisius. Tidak mengherankan apabila sosok Pustakawan yang bertahan dan berdedikasi tinggi di perpustakaan menerima imbas pencitraan tidak menguntungkan dengan masuknya para pendatang buangan.

Menurut Ahmad dalam makalahnya ditegaskan bahwa ada lima hal mengapa kiprah Pustakawan belum menyentuh masyarakat luas sehingga citra Pustakawan belum sepenuhnya positif, yaitu

1) Pustakawan terjebak didalam rutinitas kerja,

2) jumlah Pustakawan profesional yang masih sedikit,

3) Pustakawan enggan menunjukkan jati dirinya,

4) Pustakawan tidak komunikatif,

5) pihak berwenang masih fokus pada pembangunan fisik.

\section{E. Citra Baru Pustakawan}

Are we responsible for our own image? Is there anything we can do about it? Remember, although it may not seem altogether fair, we are, 
ultimately, responsible for our own image, our own reputation.

Only we, as individuals, can alter this rather dismal portrayal. We have to move beyond the bun, and show the world there is more to us than our perceived stereotype. (Hall, 1992)

Sudah pasti Pustakawan sangat dirugikan dengan pencitraan yang selama ini digambarkan. Pencitraan baru harus dimunculkan bagi terbentuknya gambaran Pustakawan yang profesional seutuhnya sehingga Pustakawan tidak lagi menjadi sosok yang terpinggirkan. Steve Arnold, eksekutif perusahaan teknologi informasi mengatakan "The librarian, for the first time, is able to be seen as a professional with a set of skills and contributions comparable to those of other professions, that have in some cases overshadowed them for so long ... Those who don't feel comfortable with change are going to be marginalized,"

Siapa yang dapat merubah citra Pustakawan? Jawabannya sederhana: 'Pustakawan sendiri!' Sekelompok Pustakawan pria tampan mencoba membalikkan citra Pustakawan yang buruk menjadi sosok yang professional dan glamor melalui kegiatan bertajuk the It Gets Better Project. Proyek ini merupakan kumpulan 12 belas pria tampan berprofesi sebagai Pustakawan dengan menampilkan dirinya dalam berbagai gaya untuk kalender 2012 dalam dua belas sesi pemotretan mulai dari menonjolkan sisi macho seorang pria melalui pose telanjang yang ada di bulan Januari sampai pose telanjang dada berdiri di depan cermin sambil menggosok gigi untuk bulan Desember. Von, seorang Pustakawan dan kandidat doktor yang juga model kalender bulan Juni, mengatakan "we can't just leave it to others to tell the people who we are; that's why the stereotypes about librarians continue to flourish. We have to be the ones to go out there and tell people who we are. It's not enough to complain about inaccurate images of librarians; we must be able to present alternative, positive images in movies, books and, yes, blogs." And, obviously, in calendars".

Potret buram harus ditutup sampai disini dan digantikan 
dengan yang baru. Teknologi berkembang dengan begitu pesat. Pustakawan harus menjadi agent of change / agen pembaharu. Bukti nyata harus segera diwujudkan. Pustakawan harus melakukan apa yang seharusnya dilakukan: memperbaiki kinerja dan meningkatkan kapasitas. Dua keterampilan, hard skill dan soft skill, sudah saatnya dimiliki dan diimplementasikan didalam kehidupan sehari-hari baik didalam pekerjaan maupun didalam pergaulan sosial. Visibilitas Pustakawan harus sering dilakukan untuk mendapat gambaran Pustakawan yang representatif seutuhnya. Perubahan untuk mendapat pencitraan baru dilakukan secara sistematis sehingga kepercayaan publik terhadap sosok Pustakawan tidak lagi sekedar wacana.

Pustakawan bukanlah katak didalam tempurung yang pengetahuannya sebatas pada dunia kepustakawanan saja. Pustakawan memiliki wawasan yang begitu luas. Pustakawan orang yang dengan lantang dan berani menentang sencorship karena prinsip-prinsip kepustakawanan yang dianutnya.
Tidak seperti para profesional lain yang begitu kesohor dan mempunyai citra terhormat yang mempunyai pelanggan tertentu dengan bayaran mahal sehingga mengharuskannya menjadi seseorang yang know everything about something. Seorang Pustakawan sangat berbeda. Client yang datang ke perpustakaan tidak berasal dari satu profesi saja tetapi mereka berasal dari berbagai kalangan dengan latar belakang pendidikan yang berbeda-beda. Mereka datang ke perpustakaan memerlukan bantuan Pustakawan didalam memenuhi kebutuhan informasinya. Hal ini memaksa pustakawan untuk menjadi seseorang yang know something about everything. Wawasan yang luas menjadi suatu keniscayaan untuk dapat memberikan layanan prima dan memuaskan pelanggan (baca: Pemustaka).

Bukan sebagai seorang penganut silent is golden, Pustakawan harus terbuka dan menunjukkan kemampuan berbicara didalam setiap kesempatan bersosialisasi dengan kelompok sosial lainnya. Kehidupan sosial menjadi begitu penting untuk ajang menampilkan 
citra diri. Dengan komunikasi yang baik didalam pergaulan baik di lingkungan akademis maupun linkungan sosial lainnya, Pustakawan akan mampu 1) bekerjasama dengan staf pengajar didalam penyediaan bahan perpustakaan yang harus ada di perpustakaan untuk menunjang kegiatan belajar mengajar, 2) memberikan literasi informasi dengan bernas, 3) bersosialisasi dengan kelompok manapun juga tanpa harus merasa "minder", dan sekaligus 4) mempengaruhi orang lain bahwa sosok Pustakawan tidak seperti yang digambarkan selama ini.

Jika selama ini Pustakawan banyak berperan di belakang layar dan posisi mereka digantikan oleh banyak figur publik lain yang tampil untuk perpustakaan atau mewakili perpustakaan, sudah saatnya Pustakawan tampil mewakili dirinya sendiri mempromosikan perpustakaan dan menunjukkan jati dirinya. Semakin sering Pustakawan tampil pada acara publik akan semakin dikenal sosoknya dengan baik.

Dalam satu artikel berjudul Membangun citra Pustakawan Indonesia, dinyatakan bahwa ada empat hal yang bisa dilakukan Pustakawan untuk mendapat citra baru, yaitu: 1) memperluas wawasan makro, 2) meningkatkan frekuensi keterlibatan didalam dunia pendidikan, literasi, dan sosial, 3) meningkatkan kemampuan kita mempengaruhi orang lain, dan 4) memperbanyak figur publik. (http://www.bit.lipi.go.id/masyara kat-

literasi/index.php/membanguncitra-pustakawan-indonesia).

\section{F. SIMPULAN}

Perkembangan teknologi informasi yang pesat menjadikan Pustakawan seseorang yang technology savvy tanpa harus meninggalkan keahlian tradisional yang dimiliki. Produk yang dihasilkan pustakawan mampu membuat induk organisasi dimana perpustakaan bernaung menjadi terangkat karenanya. Masalah yang dihadapi adalah bagaimana Pustakawan membalikkan persepsi abad pertengahan tentang diri mereka menjadi persepsi hari ini yang dapat disejajarkan dengan sosok profesional lain yang memiliki kompetensi dan berkelayakan. 
Usaha-usaha pembalikan persepsi negatif untuk meraih kepercayaan publik bahwa Pustakawan adalah sosok yang pantas dan berhak mendapat amanat untuk memegang kekuasaan harus dilakukan dengan sistematis. Pustakawan harus mampu menonjolkan diri untuk diekspos, tanpa menjadi narsis, agar publik diyakinkan bahwa sosok Pustakawan masa kini adalah sosok yang representatif seutuhnya.

Sebagian orang menyarankan Pustakawan agar berpindah menjadi tenaga fungsional lain agar mendapat gaji dan tunjangan yang lebih besar untuk dapat berkehidupan layak begitu mengetahui Pustakawan mempunyai latar belakang pendidikan tinggi. Ouch! Tunggu dulu! Pustakawan, tunjukkan gregetmu! Begitu sulit mengejar dan mendapat MLIS atau gelar yang ekuivalen untuk menjadi seorang Pustakawan. Tunjukkan jati diri sehingga orang akan berkata "You don't look like a librarian" tetapi dengan lantang tetap mengatakan "and I am proud to call myself a librarian".

\section{G. DAFTAR PUSTAKA}

Achmad. Pustakawan ..... Mana Gregetmu. Makalah disampaikan pada Kongres VII Ikatan Pustakawan Indonesia dan Seminar Ilmiah. Jakarta, 20-23 November 1995.

Beveridge, Sydney, Weber, Susan dan Andrew, A. Beveridge Librarians in the U.S. from 1880-2009: An analysis using 120 years of census data. http://blog.oup.com/2011/06/li brarian-census/. (Akses 29 Januari 2012)

Carmichael, James V., Jr. "The Male Librarian and the Feminine Image: A Survey of Stereotype, Status, and Gender Perceptions. (Akses 31 Januari 2012)

DarLynn Nemitz. Male Librarians: stereotypes and role models. http://besser.tsoa.nyu.edu/im pact/f01/Focus/Image/DarLyn n/dntopic1.htm (Akses 29 Januari 2012)

Gordon, Rachel Singer. The Accidental Library Manager. Medford, New Jersey: Information Today, Inc., 2005. 
http://bensguide.gpo.gov/benfrank lin/librarian.html (Akses 26 Januari 2012)

http://www.laurabushfoundation.o rg/mrsbush.html (Akses 15 Maret 2011)

http://www.merriamwebster.com/dictionary/imag e, (Akses 15 Januari 2012)

http://www.pemustaka.com/pusta kawan (Akses 15 Maret 2011) Image of librarians. http://liswiki.org/wiki/Image_ of_librarians (Akses 26 Januari 2012)

Librarian: Educational Requirements to $\mathrm{Be} a$ Librarian. http://educationportal.com/articles/Librarian \%3A_Educational_Requireme nts_to_Be_a_Librarian.html (Akses 15 Maret 2011)

Librarians checked out in 'Men of the Stacks' Calendar. http://www.guardian.co.uk/b ooks/2011/sep/29/librariansmen-of-the-stacks-calendar (Akses 29 Januari 2012)

Librarians in popular culture. http://en.wikipedia.org/wiki/ Librarian. (Akses 4 Januari 2012)
Librarians in the Movies. http://www.slais.ubc.ca/cours es/libr500/03-04wt1/assignments/www/K_Mu lhern/movies.htm (Akses 26 Januari 2012)

Librarians on Television. http://www.slais.ubc.ca/cours es/libr500/03-04wt1/assignments/www/K_Mu lhern/tele.htm (Akses 26 Januari 2012)

Lina Khoerunnisa . Dicari Pustakawan Ideal Guna Membangun Citra Pustakawan Indonesia 2010. http://www.pemustaka.com/ dicari-pustakawan-idealguna-membangun-citrapustakawan-indonesia2010.html. (Akses 5 Januari 2012)

Membangun

Citra Pustakawan Indonesia. http://www.bit.lipi.go.id/mas yarakat-

literasi/index.php/membangu n-citra-pustakawan-indonesia (Akses 31 Januari 2012) The New Lexicon Webster's Dictionary of the English Language. New York: Lexicon Publications, Inc., 1989, p. 483.

Perundang-Undangan. http://www.presidenri.go.id/i ndex.php/uu/peraturan- 
presiden/ (Akses 4 Januari 2012)

Ponzoni, Patrizia. Librarians' Image And Identity: A Research Proposal about the professional community of Poletti library. (Akses 3 Februari 2012)

Raish, Martin. Librarians In The Movie: An Annotated Filmography. http://emp.byui.edu/RAISHM /films/introduction.html (Akses 26 Januari 2012)

Ruth A. Kneale. You Don't Look Like a Librarian! Librarians' views of public perception in the Internet age. http://www.librarianimage.net/perc.html (Akses 26 Januari 2012)

Stereotypes Of Librarians. http://home.earthlink.net/ cy berresearcher/stereotypes.ht m (Akses 26 Januari 2012)

Undang-Undang Republik Indonesia Nomor 43 Tahun 2007 Tentang Perpustakaan. Perpustakaan Nasional RI., 2007.

Walker, Stephen dan Lawson, V. Lonnie. The Librarian Stereotype And The Movies. http://wings.buffalo.edu/publ ications/mcjrnl/v1n1/image.ht ml (Akses 26 Januari 2012) 
“Perpustakaan adalah institusi pengelola koleksi karya tulis, karya cetak, dan/atau karya rekam secara profesional dengan sistem yang baku guna memenuhi kebutuhan pendidikan, penelitian, pelestarian, informasi, dan rekreasi para pemustaka."

Pasal 1 Undang-undang Republik Indonesia Nomor 43 Tahun 2007 tentang Perpustakaan 